\title{
Hepatocellular Carcinoma and Nuclear Paraspeckles: Induction in Chemoresistance and Prediction for Poor Survival
}

\author{
Sonja M. Kesslera Kevan Hosseinia Usama Khamis Hussein ${ }^{b, c, d} \quad$ Kyoung Min Kimm ${ }^{b, c}$ \\ Markus List ${ }^{e f f} \quad$ Christina S. Schultheißa Marcel H. Schulz ${ }^{e, g, h, i} \quad$ Stephan Laggaia \\ Kyu Yun Jang ${ }^{b, c}$ Alexandra K. Kiemera
}

\begin{abstract}
aDepartment of Pharmacy, Pharmaceutical Biology, Saarland University, Saarbrücken, Germany, 'Department of Pathology, Chonbuk National University Medical School, Jeonju, Republic of Korea, 'Research Institute of Clinical Medicine of Chonbuk National University-Biomedical Research Institute of Chonbuk National University Hospital and Research Institute for Endocrine Sciences, Jeonju, Republic of Korea, dFaculty of Science, Beni-Suef University, Beni Suef, Egypt, eDepartment for Computational Biology and Applied Algorithmics, Max Planck Institute for Informatics, Saarland Informatics Campus, Saarland University, Saarbrücken, Germany, fBig Data in BioMedicine Group, Chair of Experimental Bioinformatics, TUM School of Life Sciences Weihenstephan, Technical University of Munich, Freising, Germany, ${ }^{9}$ Cluster of Excellence in Multimodal Computing and Interaction, Saarland Informatics Campus, Saarland University, Saarbrücken, Germany, hInstitute for Cardiovascular Regeneration, Goethe-University Hospital, Frankfurt, Germany, 'German Centre for Cardiovascular Research (DZHK), Partner site RheinMain, Frankfurt, Germany
\end{abstract}

\section{Key Words}

Liver cancer • Chemosensitivity • Chemotherapy • Therapy response • IncRNA • MALAT1 • NEAT2 $\bullet$ mRNA stability $\bullet$ mRNA decay • Actinomycin D

\footnotetext{
Abstract

Background/Aims: Hepatocellular carcinoma (HCC) represents the second most common cause of cancer-related deaths worldwide, not least due to its high chemoresistance. The long non-coding RNA nuclear paraspeckle assembly transcript 1 (NEAT1), localised in nuclear paraspeckles, has been shown to enhance chemoresistance in several cancer types. Since data on NEAT1 in HCC chemosensitivity are completely lacking and chemoresistance is linked to poor prognosis, we aimed to study NEAT1 expression in HCC chemoresistance and its link to HCC prognosis. Methods: NEAT1 expression was determined in either sensitive, or sorafenib, or doxorubicin resistant HepG2, PLC/PRF/5, and Huh7 cells by qPCR. Paraspeckles were detected by immunostaining of paraspeckle component 1 (PSPC1) in cell culture and in a cohort of HCC patients. PSPC1 expression was correlated with clinical data. The expression of transcript

S.M. Kessler, K. Hosseini and U.K. Hussein contributed equally to this work.

\begin{tabular}{ll}
\hline Alexandra K. Kiemer & Pharmaceutical Biology, Saarland University, Department of Pharmacy, 66123 Saarbrücken (Germany); \\
and Kyu Yun Jang, & Dept. of Pathol., Chonbuk Nat. Univ. Med. School, 567 Baekje-daero, Dukjin-gu, Jeonju, 54896 (South Korea) \\
MD, PhD & E-Mail pharm.bio.kiemer@mx.uni-saarland.de; kyjang@chonbuk.ac.kr
\end{tabular}
}


variants of NEAT1 and transcripts encoding the paraspeckle-associated proteins was analysed in the TCGA liver cancer data set. Results: NEAT1 was overexpressed in all three sorafenib and doxorubicin resistant cell lines. Paraspeckles were present in all chemoresistant cells, whereas no signal was detected in the sensitive cells. Expression of NEAT1 transcripts as well as transcripts encoding $P S P C 1, N O N O$, and RBM14 was increased in tumour tissue. Expression of PSPC1, NONO, and RBM14 transcripts was significantly associated with poor survival, whereas NEAT1 expression was not. Immunohistochemical analysis revealed that nuclear and cytoplasmic PSPC1-positivity was significantly associated with shorter overall survival of HCC patients. Conclusion: Our data show an induction of NEAT1 in HCC chemoresistance and a high correlation of transcripts encoding paraspeckle-associated proteins with poor survival in HCC. Therefore, NEAT1, PSPC1, NONO, and RBM14 might be promising targets for novel HCC therapies, and the paraspeckle-associated proteins might be clinical markers and predictors for poor survival in HCC.

(C) 2019 The Author(s). Published by Cell Physiol Biochem Press GmbH\&Co. KG

\section{Introduction}

Liver cancer - with its predominant form hepatocellular carcinoma (HCC) - represents the second most common cause of cancer-related death worldwide [1, 2]. Although improvements in the survival of patients with HCC have been achieved in the past two decades, the prognosis of HCC remains one of the worst amongst all cancers [2,3]. One major issue regarding the therapy of HCC is chemoresistance: no effective conventional systemic chemotherapy for patients with advanced hepatocellular carcinoma has been established until now, resulting in poor prognosis of these patients [4]. The response rate for sorafenib, the only approved drug besides regorafenib for systemic treatment in the late stage of the disease, is below $3.5 \%$. A systemic combination of sorafenib and doxorubicin also leads to poor response rates up to a maximum of 6\% [5]. Chemoresistance is closely linked to a poor prognosis, not only in HCC, but also in other cancer types [6-8].

It is known that only $2 \%$ of the genome encodes for proteins, whereas the considerably larger part of the transcribed human genome consists of non-coding sequences [9]. One of these sequences is the long non-coding RNA nuclear paraspeckle assembly transcript 1 (NEAT1). NEAT1 is located in nuclear paraspeckles [10], which are found in the nucleus' interchromatin space $[11,12]$. The two transcript variants of NEAT1 described in the literature are the short NEAT1_v1 (NEAT1E, $3.7 \mathrm{~kb}$ in length) and the long NEAT1_v2 (NEAT1202, NEAT1 $\beta, 23 \mathrm{~kb}$ in length). Ensembl lists four additional transcript variants (NEAT1-201, 203 -205) (Fig. 1). Although NEAT1_v1 and NEAT1-202/v2 transcript variants are essential for the integrity of paraspeckles, the long transcript variant is essential for de novo paraspeckle assembly $[11,12]$. The biological role of paraspeckles is widely unknown, not least due to the lack of an altered phenotype in Neat1 knock-out mice [13]. Recently, it has been suggested that NEAT1 enhances chemoresistance in several cancer cell types [14]. Since data on NEAT1 in HCC chemosensitivity are completely lacking, we aimed to study NEAT1 expression as well as paraspeckle formation in HCC and in chemoresistant compared to chemosensitive HCC cell lines.

With the recently described effect of increased HCC cell proliferation induced by NEAT1_ $v 1 / 202 / v 2$ in HCC cells $[15,16]$, we also sought to determine whether its expression might serve as a prognostic clinical marker.

\section{Materials and Methods}

\section{Cell culture}

HepG2, PLC/PRF/5, and Huh7 cells were cultured in RPMI-1640 medium with $10 \%$ fetal calf serum, $1 \%$ penicillin/streptomycin and $1 \%$ glutamine (Sigma-Aldrich, Taufkirchen, Germany) at $37^{\circ} \mathrm{C}$ and $5 \%$ $\mathrm{CO}_{2}$. To induce and maintain chemoresistance, cells were regularly treated with either doxorubicin (Sigma- 


\section{Cellular Physiology Cell Physiol Biochem 2019;52:787-801 \\ \begin{tabular}{l|l} 
Dol: $10.33594 / 000000055$ \\
and Biochemistry
\end{tabular} $\begin{aligned} & \text { Published online: } 5 \text { April 2019 The Author(s). Published by } \\
& \text { Cell Physiol Biochem Press GmbH\&Co. }\end{aligned}$ \\ Kessler et al.: Paraspeckles in HCC}

Aldrich) or sorafenib (Biomol, Hamburg, Germany) as previously described [17]. Chemoresistance was regularly confirmed via IC50 determination by MTT assay. All cell lines were tested regularly for mycoplasma contamination and found negative. All cell lines were authenticated by the DSMZ (Braunschweig, Germany).

RNA stability was analysed using the transcriptional inhibitor actinomycin D as previously described $[18,19]$. Huh7, PLC/PRF/5, and HepG2 cells treated for $0.5,1,2$, and 4 hours with actinomycin D $(10 \mu \mathrm{M})$ or DMSO as vehicle. RNA half-life of NEAT1_v1/201/202/v2 transcripts analysed by qPCR.

\section{RNA isolation and $q P C R$}

Total RNA was extracted using Qiazol lysis reagent (Qiagen, Hilden, Germany) according to the manufacturer's protocol. Residual genomic DNA was removed by treatment with DNase I (Ambion / Invitrogen, Carlsbad, California, USA). Reverse transcription was performed using the High-Capacity cDNA Reverse Transcription Kit (Applied Biosystems, Foster City, California, USA) as recommended by the supplier. Real-time quantitative polymerase chain reaction (qPCR) was performed in a CFX96 cycler (BioRad, München, Germany) with 5× HOT FIREPol ${ }^{\circledR}$ EvaGreen ${ }^{\circledR}$ qPCR Mix Plus (Solis BioDyne, Tartu, Estonia). All samples were estimated in triplicate. The following primers were used (see also Fig. 1): NEAT1_v1/202/ $v 2$ forward: TGCTACAAGGTGGGGAAGACTG; NEAT1_v1/202/v2 reverse: CCCACACCCCAAACAAAACAA; NEAT1_v1/201/202/v2 forward: CCCCTTCTTCCTCCCTTTAAC; NEAT1_v1/201/202/v2 reverse: CCTCTCTTCCTCCACCATTAC; NEAT1-202/v2 forward: TTTCAAAGGGAGCAGCAAGGG; NEAT1-202/v2 reverse: ACGGCACAGGCAAATAAGACAC. Annealing temperature was $60^{\circ} \mathrm{C}$ for $N E A T 1 \_v 1 / 202 / v 2$ and $N E A T 1 \_v 1 / 201 / 202 / v 2$, and $64^{\circ} \mathrm{C}$ for $N E A T 1-202 / v 2$. Primer concentrations for all three were $0.25 \mu \mathrm{M}$. Efficiency for each experiment was determined using a dilution series. Gene expression was normalised to ACTB mRNA values.

\section{Immunofluorescence}

Cells were grown on coverslips overnight and fixed with 4\% paraformaldehyde for 15 min on ice. After permeabilisation with 1\% Triton X 100 for 15 min, unspecific binding was blocked using a combination of $2 \%$ bovine serum albumin and 10\% FCS for $1.5 \mathrm{~h}$. The cells were incubated with paraspeckle component 1 (PSPC1) antibody (1:20 dilution; sc-374181, Santa Cruz, CA, USASA) overnight at $4^{\circ} \mathrm{C}$. After washing, the secondary antibody, goat anti-mouse AlexaFluor 488 (Invitrogen, Karlsruhe, Germany), was added for 1.5 $\mathrm{h}$ at room temperature. After washing and adding DAPI (Sigma-Aldrich) for nuclear staining, coverslips were mounted with FluorSave ${ }^{\mathrm{TM}}$ (Calbiochem, Sandhausen, Germany). Images were obtained and analysed with an Axio Observer Z1 epifluorescence microscope equipped with an AxioCam Mrm (Zeiss, Oberkochen, Germany). All cell images were obtained using either a 63x objective (for Huh7 and PLC/PRF/5 cells), or a 100x objective (for HepG2 cells). Data were obtained and analysed using the AxioVision software (Zeiss).

\section{TCGA data}

RNAseq expression data were obtained from The Cancer Genome Atlas pan cancer dataset produced via Toil [20]. RSEM [21] reported transcripts per million values were downloaded via the UCSC Xena Browser (https://xenabrowser.net) and comprised 369 primary solid tumour as well as 50 matched non-tumour tissue samples for gene expression. Only transcript variants with an average expression rate of $\log 2$ (TPM +0.001 ) $>0$ were considered for analysis in the R statistical environment (v. 3.4.2). For survival analysis we considered two groups (split at 50\% quantile) and three groups (split at 25\% and 75\% quantiles), respectively. Significance of differences between survival curves was computed with a log rank test using the survival R package (Therneau and Grambsch, 2000). Further, we determined pairwise Pearson correlation of transcript expression and plotted them using the corrplot $\mathrm{R}$ package [22].

\section{Hepatocellular carcinoma patients and tissue samples}

One hundred sixty hepatocellular carcinomas (HCCs), from which the medical records, the histologic slides, and paraffin tissue blocks were available, were included into this study. The HCC patients underwent radical resection in the Chonbuk National University Hospital between January 1998 and August 2009. The HCC cases were reviewed and classified according to the criteria of the World Health Organization Classification [23] and the staging system of the American Joint Committee on Cancer [24]. This study obtained institutional review board approval from the Chonbuk National University Hospital, and the requirement for informed consent was waived (IRB number, CUH 2018-03-002). 


\section{Cellular Physiology Cell Physiol Biochem 2019;52:787-801 \\ \begin{tabular}{ll|l} 
and Biochemistry $\begin{array}{l}\text { DOl: 10.33594/000000055 } \\
\text { Published online: } 5 \text { April 2019 }\end{array}$ & $\begin{array}{l}\text { O } 2019 \text { The Author(s). Published by } \\
\text { Cell Physiol Biochem Press GmbH\&Co. KG }\end{array}$ \\
\cline { 2 - 3 } &
\end{tabular} \\ Kessler et al.: Paraspeckles in HCC}

Immunohistochemical staining and scoring of tissue microarrays

Immunohistochemical staining was performed on tissue microarray (TMA) sections with one 3.0 $\mathrm{mm}$ core per HCC cases. Antigen retrieval for the tissue sections was performed in a microwave oven for 12 minutes in Dako Target Retrieval Solution (pH 6.0, DAKO, Glostrup, Denmark). A primary antibody for PSPC1 in a 1:200 dilution (ThermoFisher Scientific, Rockford, IL, USA) was used for immunohistochemical detection. Immunohistochemical scoring for PSPC1 was performed by two pathologists (KYJ and KMK) with consensus for the cytoplasmic and nuclear expression of PSPC1. The scoring was performed without information of the clinicopathological factors of HCC patients. The immunohistochemical score was obtained by adding the intensity scores ( 0 , no staining; 1 , weak staining; 2 , intermediate staining; 3 , strong staining) and the area scores $(0$, no stained cells; $1,1 \%$ positive; $2,2-10 \%$ positive; $3,11-33 \%$ positive; $4,34-66 \%$ positive; $5,67-100 \%$ positive) [25-27]. The sum score ranged from zero to eight. Subsequently, receiver operating characteristic curve analysis was performed to estimate death of HCC patients by determining positivity for cytoplasmic and nuclear expression of PSPC1 [26, 27].

\section{Statistical analysis}

Data analysis and statistics were performed with OriginPro 8.6G (OriginLab Corporation, Northampton, USA) and SPSS software (IBM, version 20.0, CA). Values were expressed as box plots with 25th/75th percentile boxes, geometric medians (line), means (square), and 10th/90th percentile as whiskers. Statistical differences were calculated using an independent two-sample t-test or Mann-Whitney test as indicated depending on whether the data were normally distributed. The survival analysis of TMAs was performed for the overall survival (OS) and relapse-free survival (RFS). The follow-up end point was June 2013. In OS analysis, the event was death of patients by HCC, and the patients who were alive at last contact or died from other causes were treated as censored. In RFS analysis, the event was relapse of HCC and death of patients from HCC. The patients who were alive at last contact without relapse of the tumor or died from other causes were treated as censored. Univariate and multivariate Cox proportional hazards regression analyses, Kaplan-Meier survival analysis, and Pearson's chi-square test were used. The $P$ values less than 0.05 were considered statistically significant.

\section{Results}

To determine a possible role of NEAT1 in HCC chemoresistance, we established human hepatoma cells (HepG2, PLC/PRF/5 and Huh7) resistant to the chemotherapeutics sorafenib or doxorubicin [17]. We measured NEAT1 expression in these cells using three primers denoted as NEAT1_v1/202/v2, NEAT1_v1/201/202/v2, and NEAT1-202/v2 (Fig. 1, Supplementary Table S1 - all supplementary material available online at www.cellphysiolbiochem.com). NEAT1_v1/202/v2 was significantly overexpressed in all three sorafenib and doxorubicin resistant cell lines (Fig. 2A, B). In addition, sorafenib resistant HepG2 and Huh7 cells as well as doxorubicin resistant PLC/PRF/5 and Huh7 cells showed an increased expression of NEAT1_v1/201/202/v2 and NEAT1-202/v2 (Fig. 2A, B).

NEAT1-202/v2 was found to be essential for de novo paraspeckle assembly [28]. Due to the overexpression of $N E A T 1-202 / v 2$, we hypothesized that chemoresistant hepatoma cell lines have an increased paraspeckle formation. Therefore, cells were stained for paraspeckle component 1 (PSPC1). In fact, positive signals were detected in all chemoresistant cells, whereas no signal could be detected in the control cells (Fig. 3). The most intense paraspeckle staining was observed in Huh7 cells, which showed the highest NEAT1-202/v2 expression (Fig. 2A, B). Our data suggest that doxorubicin resistance induces paraspeckle formation slightly more intensely compared to sorafenib resistance, which is in accordance with the higher NEAT1-202/v2 RNA expression in doxorubicin resistant PLC/PRF/5 and Huh7 cells (Fig. 2B, 3). PLC/PRF/5 and Huh7 cells showed no differences regarding this aspect (Fig. 3).

Our data show a distinct connection of chemoresistance, NEAT1 induction, and paraspeckle formation in three different HCC cell lines. Accordingly, two recently published papers described that NEAT1_v1/202/v2 knockdown resulted in elevated apoptosis and reduced viability / proliferation in different HCC cell lines $[15,16]$. Since our data indicate 


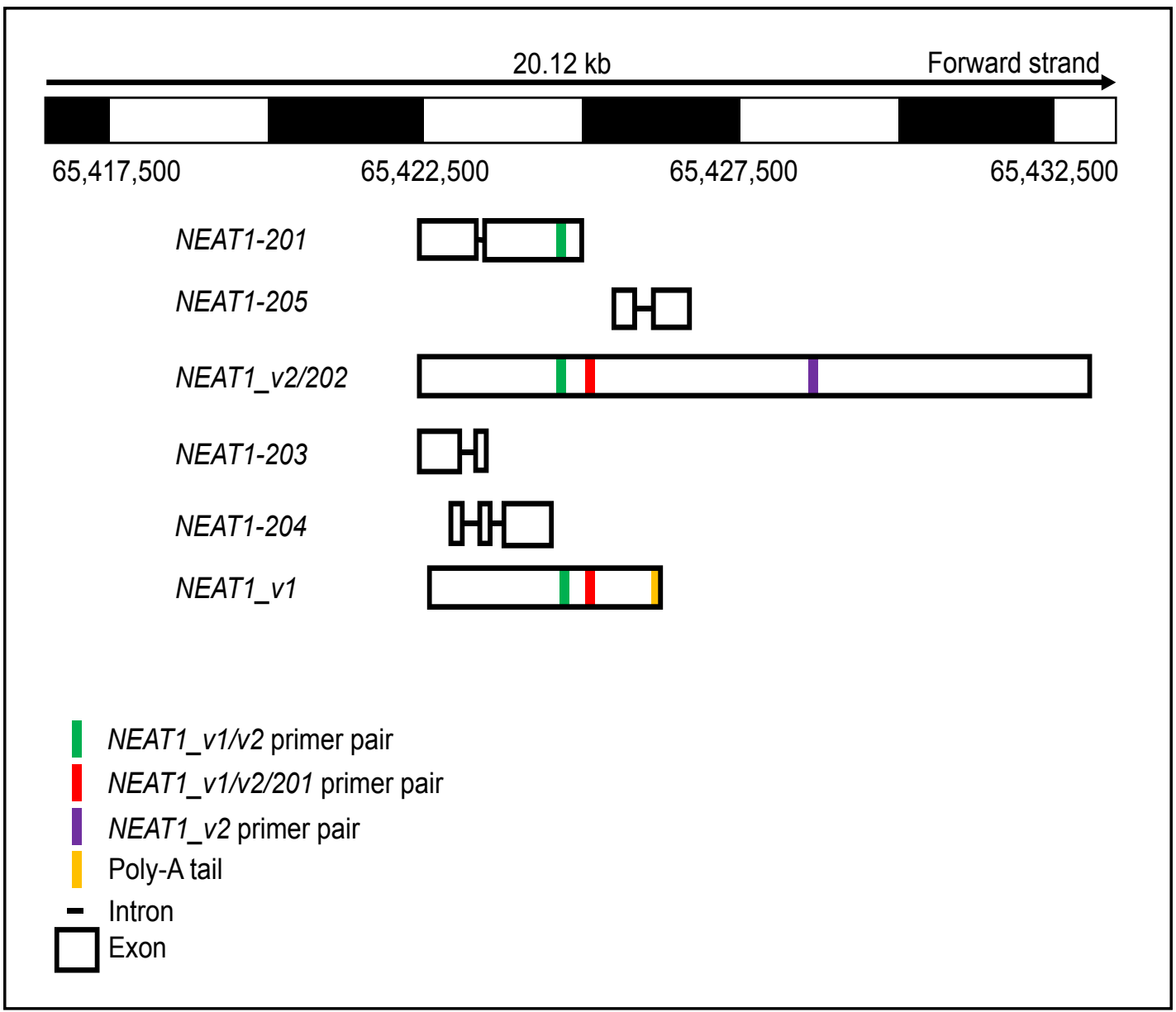

Fig. 1. NEAT1 gene locus. Size and location of NEAT1 transcript variants (Supplementary Table S1) on the NEAT1 gene locus on chromosome 11 (schematic). Coloured areas indicate regions amplified in the respective qPCR reaction. Scheme is not drawn to scale.

that chemosensitive cell lines do not form paraspeckles, one might speculate that NEAT1 might also act independently of paraspeckles [29].

Since previous studies had reported elevated NEAT1 in HCC in samples from up to 95 HCC compared to non-tumour liver tissues - as assessed by qPCR [30, 31], we hypothesised that NEAT1 expression might serve as a prognostic marker for HCC patients. To test this hypothesis, we first analysed the expression of total NEAT1 (sum of all variants 201-205) as well as the individual transcript variants (Fig. 1) in the TCGA dataset comprising 369 HCC tissues and 50 non-tumour tissues. We could confirm that the expression of total NEAT1 was significantly increased in the tumour tissues as were the transcript variants NEAT1201, NEAT1-202/v2, and NEAT1-205, while the expression of NEAT1-203 and NEAT1-204 was below the threshold (Fig. 4A; Supplementary Table S2).

Interestingly, though, there was no significant association with survival for any of the differentially expressed NEAT1 transcripts (Table 1; Supplementary Fig. S1).

With NEAT1 representing a critical component of paraspeckles, we wondered whether the expression of genes encoding paraspeckle proteins was upregulated in HCC. For that, we analysed the expression of transcripts encoding PSPC1, non-POU domain containing octamer binding protein (NONO), and RNA-binding motif protein 14 (RBM14) in the TCGA samples. All transcripts described in Ensembl release 91 [32] were analysed, whereby only transcripts reaching the threshold mean expression of $\log 2(\mathrm{TPM}+0.001)>0$ were taken into consideration (Supplementary Table S2). 
We found that the expression of transcripts encoding for all three paraspeckle proteins was significantly elevated in HCC. For PSPC1, this was true for both protein-coding transcripts 201 and 206 as well as for the noncoding transcripts 203 and 204 (Fig. 4B). Additionally, the expression of the protein coding NONO transcripts 201 and 202 as well as the noncoding processed transcripts 210 and 211 were significantly elevated in HCC (Fig. 4C). For $R B M 14$, the two protein-coding transcripts 201 and 202 were significantly elevated (Fig. 4D). Most interestingly, there was a significant association with poor prognosis for transcript variants of all three paraspeckle proteins (Table 1; Supplementary Fig. S2-4).

Except for RBM14202, expression levels of all protein-coding and noncoding paraspeckle associated transcripts showed distinct correlations with each other (Fig. 5).

In order to confirm association of PSPC1 with prognosis on protein level, immunohistochemistry using an additional HCC cohort consisting of 160 patients was performed. In human

A NEAT1 expression in sorafenib resistant cells

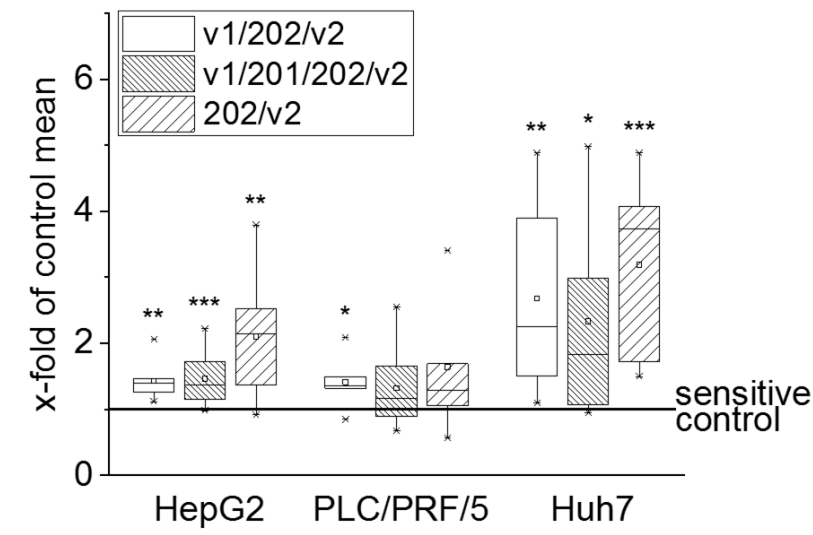

B

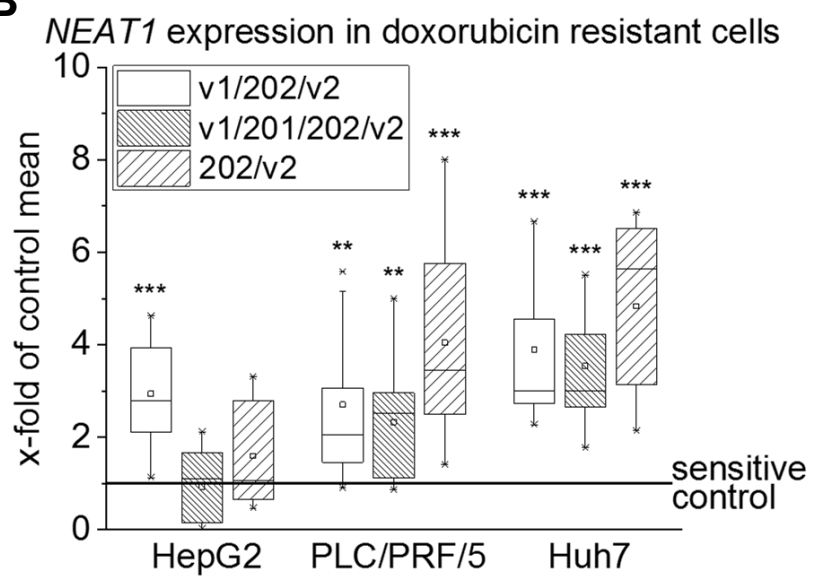

Fig. 2. NEAT1 expression in chemoresistant hepatoma cell lines. NEAT1_v1/202/v2, NEAT1_v1/201/202/v2, and NEAT1-202/v2 expression determined by qPCR in sorafenib resistant (A) and doxorubicin resistant (B) cells ( $\mathrm{n}=3$, triplicates). Data are shown as $\mathrm{x}$-fold with sensitive control cells set to 1 . Results of independent two-sample t-test or Mann-Whitney test: ${ }^{*}: \mathrm{p} \leq 0.05$; $^{* *}$ : $\mathrm{p} \leq 0.01$; $* * *: \mathrm{p} \leq 0.001$.

HCC tissue samples, PSPC1

was expressed in both the nucleus and the cytoplasm of cancer cells (Fig. 6A). The cut-off points of immunohistochemical scores for the cytoplasmic and nuclear expression of PSPC1 were eight and seven, respectively (Fig. 6B, Table 2). Cytoplasmic expression of PSPC1 was considered positive if the score was eight. Nuclear expression of PSPC1 was considered positive if the score was equal or greater than seven (Fig. 6B, Table 2). With these cut-off points, 48\% (77/160) of HCCs were classified as nuclear PSPC1 positive and 15\% (24/160) of HCCs were classified as cytoplasmic PSPC1 positive. Nuclear and cytoplasmic PSPC1 positivity were significantly associated with shorter OS and relapse-free survival (RFS) of HCC patients (Fig. 6C and Supplementary Table S3). 


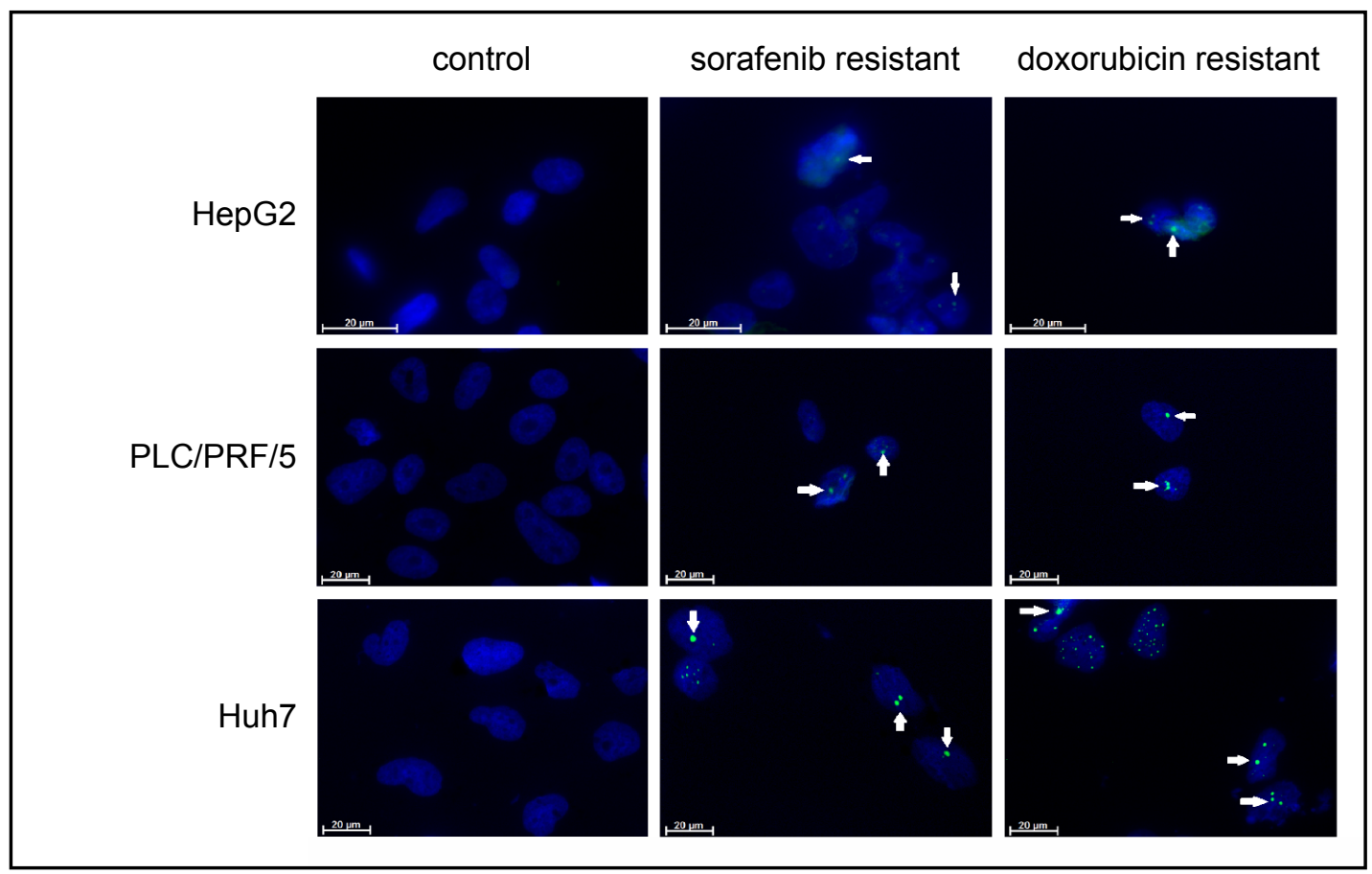

Fig. 3. Paraspeckle formation in chemoresistant human hepatoma cells. Figure shows a representative image of doxorubicin and sorafenib resistant HepG2, PLC/PRF/5 and Huh7 cells. DAPI: blue, PSPC1: green. Arrows show PSPC1 positive signals. Scale bars $=20 \mu \mathrm{m}$.

Fig. 4. NEAT1, PSPC1, NONO, and RBM14 expression in human liver tissue. Expression of total NEAT1 and its transcript variants (A) and the transcript variants of PSPC1 (B), NONO (C), and RBM14 (D) in human tumour and nontumour tissue from a TCGA data set. The figure only shows the transcript variants with an average expression rate of $\log 2$ (TPM + $0.001)>0$. Results of independent two-sample t-test or MannWhitney test: ${ }^{* *}: \mathrm{p} \leq 0.01$; $^{* *}: \mathrm{p} \leq$ 0.001 .
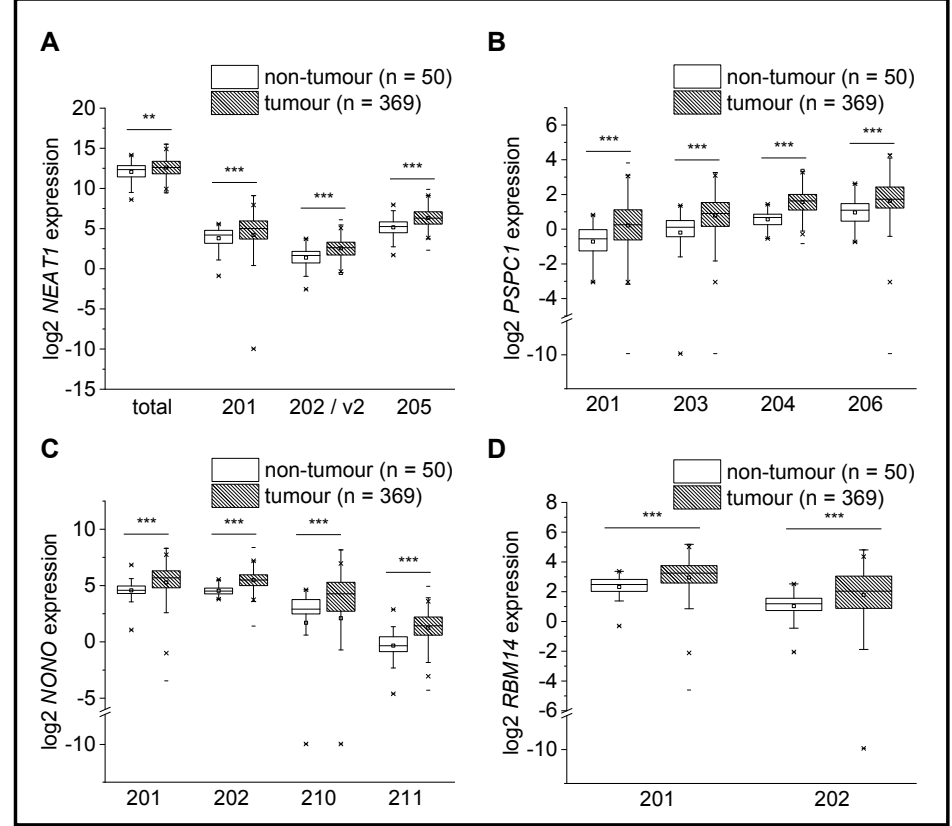
Nuclear PSPC1-positivity further correlated with the absence of liver cirrhosis (Table 3).

Beside parameters, which are commonly known to be associated with survival of HCC patients, such as age, serum AFP levels, and tumor stage, nuclear expression of PSPC1 was significantly associated with survival of HCC patients in a multivariate analysis (Table 4). Nuclear expression of PSPC1 indicated a 1.978-fold (95\% confidence interval; 1.252-3.125) greater risk in OS and a 1.566-fold (95\% confidence interval; 1.069-2.295) greater risk in RFS (Table 4).

\section{Discussion}

An implication of NEAT1 in the process of chemoresistance was previously described in human breast cancer MCF7, neuroblastoma NGP, colon carcinoma HCT116, osteosarcoma U2OS cells, and renal cell carcinoma $[14,33]$. Our study is the first to implicate NEAT1 in HCC chemoresistance: We find the variants NEAT1_v1 and NEAT1-202/v2 to be significantly overexpressed in HepG2, PLC/PRF/5, and Huh7 cells that have developed resistance against either sorafenib or doxorubicin.
Table 1. Kaplan Meier survival analysis according to the expression level of the respective transcript. Column 3: Patients were stratified into two groups, i.e. expression was above or below the median expression ( $\leq 50 \%$ vs $>50 \%$ quantile). Column 4: Patients were stratified into three groups, i.e. expression was low (below $25 \%$ expression quantile), high (above $75 \%$ expression quantile), or intermediate ( $>25 \%$ and $<75 \%$ expression quantile). $p$-values $\leq 0.05$ were considered as significant and are printed in bold letters. (TPM $+0.001)>0$. $p$-values $\leq 0.05$ were considered as significant and are printed in bold letters

\begin{tabular}{|c|c|c|c|}
\hline Gene & Transcript variant & $\begin{array}{c}\mathrm{p} \text {-value } \\
\leq 50 \% \text { vs }>50 \% \text { quantile }\end{array}$ & $\begin{array}{c}\text { p-value } \\
>25 \% \& \leq 75 \% \text { vs } \leq 25 \% \text { vs } \\
>75 \% \text { quantile }\end{array}$ \\
\hline \multirow[t]{3}{*}{ NEAT1 } & 201 & 0.1 & 0.25 \\
\hline & $202 / v 2$ & 0.53 & 0.19 \\
\hline & 205 & 0.88 & 0.25 \\
\hline \multirow[t]{4}{*}{ PSPC1 } & 201 & 0.4 & 0.4 \\
\hline & 203 & 0.0022 & 0.0092 \\
\hline & 204 & 0.075 & 0.16 \\
\hline & 206 & 0.026 & 0.071 \\
\hline \multirow[t]{4}{*}{ NONO } & 201 & 0.055 & 0.099 \\
\hline & 202 & 0.00019 & 0.00072 \\
\hline & 210 & 0.065 & 0.18 \\
\hline & 211 & 0.022 & 0.068 \\
\hline \multirow[t]{2}{*}{ RBM14 } & 201 & 0.0025 & 0.007 \\
\hline & 202 & 0.16 & 0.2 \\
\hline
\end{tabular}

Fig. 5. Pairwise correlation of transcript variants with an average expression rate of $\log 2(\mathrm{TPM}+0.001)$ $>0$ of NEAT1, PSPC1, NONO, and RBM14. The lower triangle indicates correlation coefficients numerically, whereas the upper triangle depicts them as ellipsoids. Blue indicates positive and red negative correlation as reflected by the colour legend on the right-hand side.

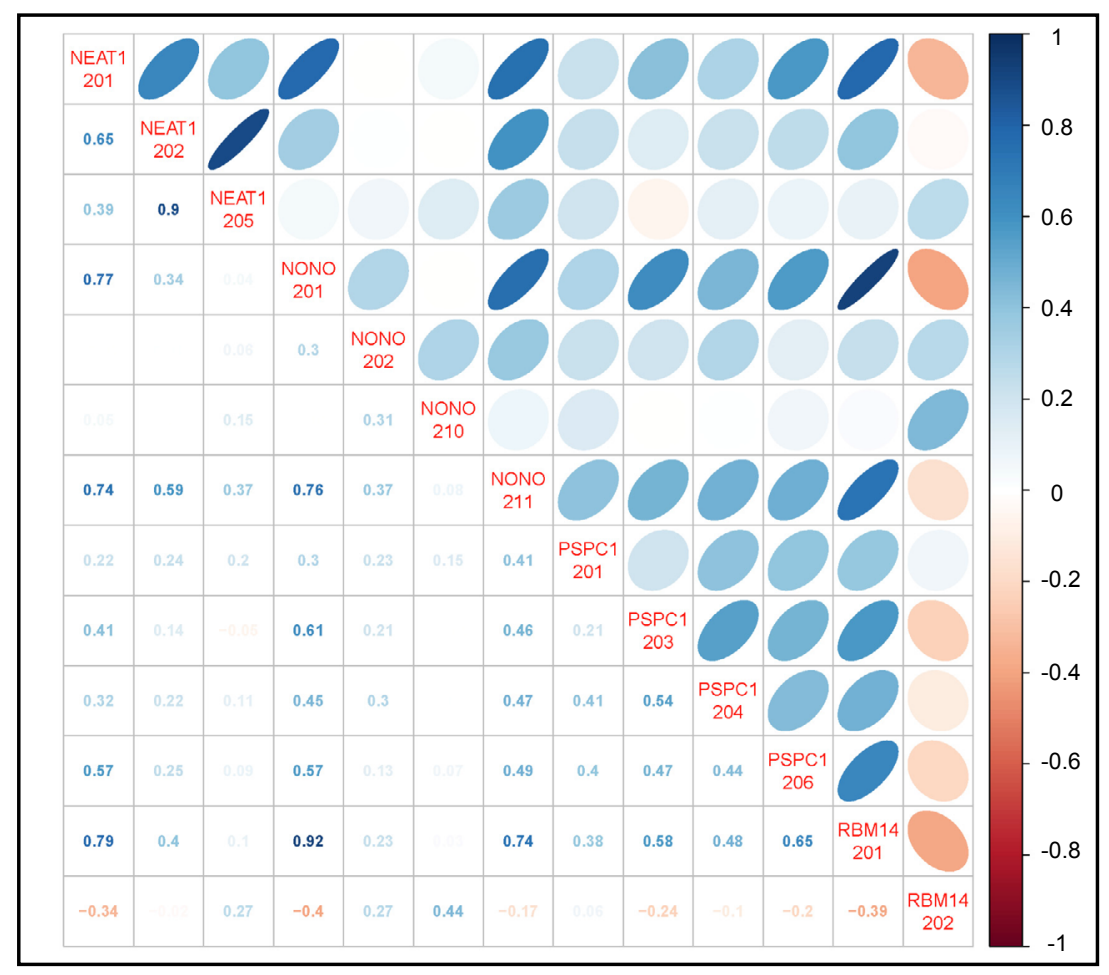


A PSPC1

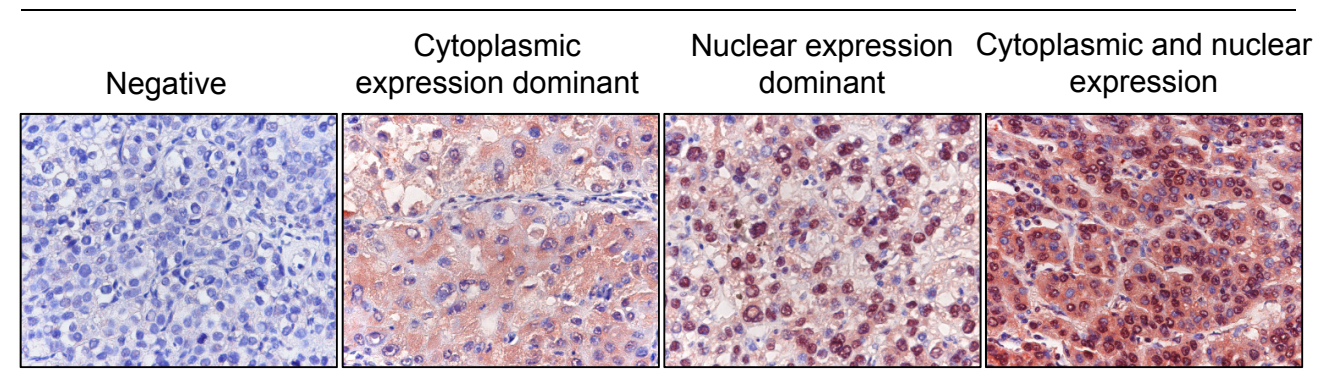

B

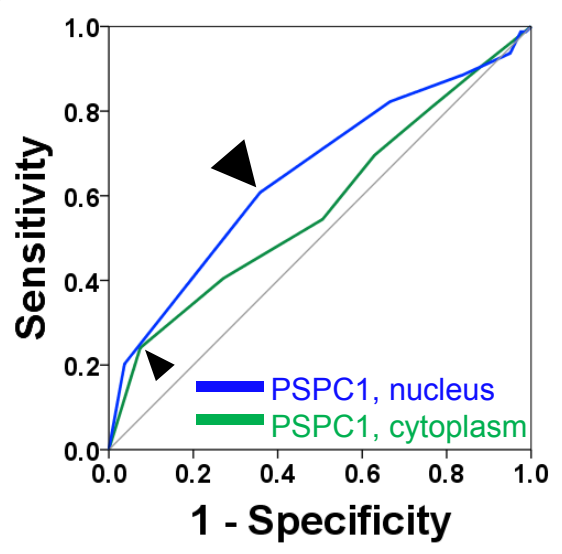

C

D
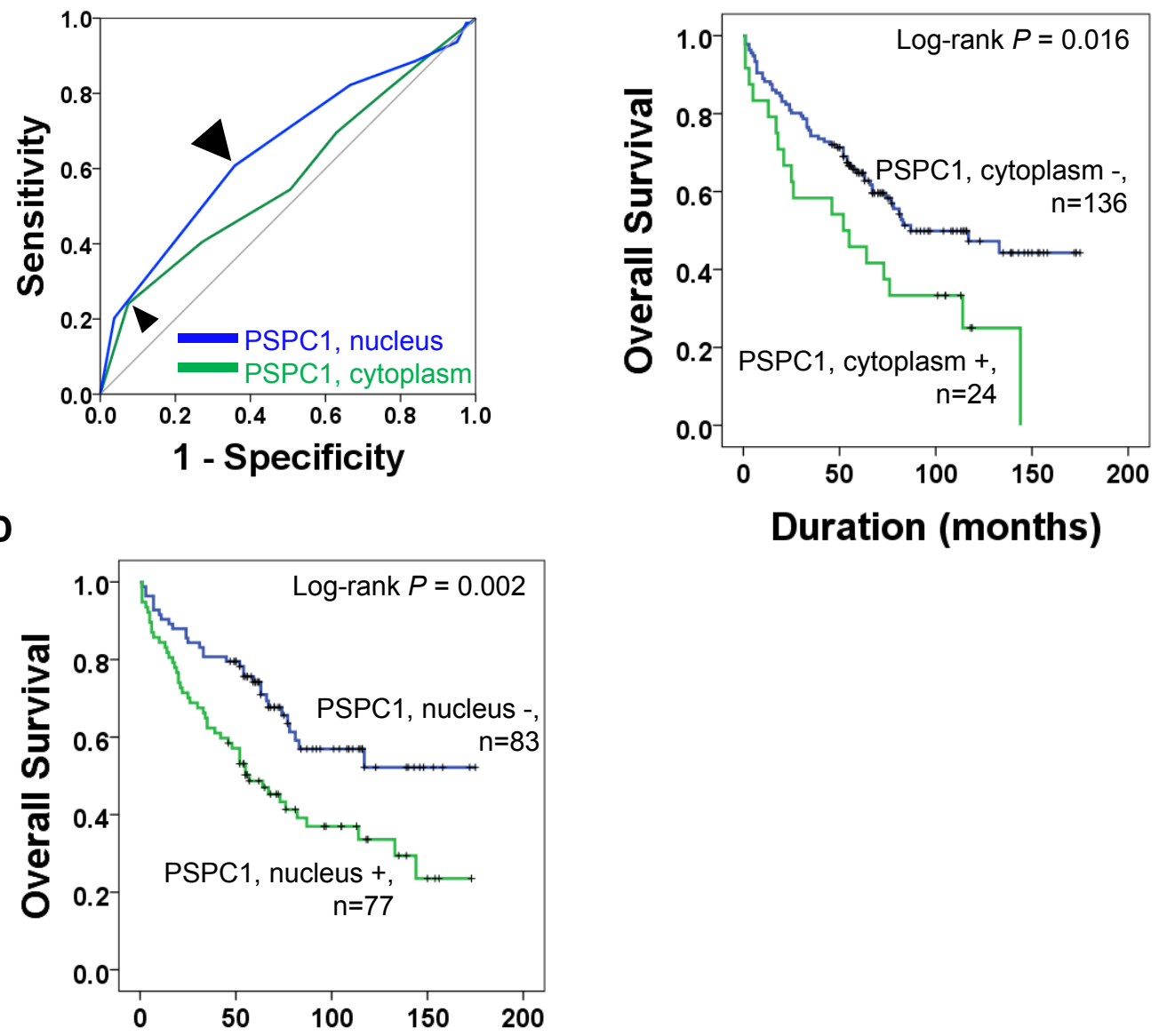

Fig. 6. Immunohistochemical detection of PSPC1 and survival analysis in 160 hepatocellular carcinoma samples. A. Representative pictures of immunohistochemical staining of PSPC1 regarding cytoplasmatic and nuclear staining of tumor cells. B. Statistical analysis to determine cut-off points for cytoplasmic and nuclear expression of PSPC1 with receiver operator characteristic curve analysis. The points with the highest area under the curve (AUC) were cut-off points for cytoplasmic and nuclear PSPC1 expression. C. Kaplan-Meier survival analysis according to cytoplasmic PSPC1 expression and nuclear PSPC1 expression for the overall survival and relapse-free survival. 


\section{Cellular Physiology Cell Physiol Biochem 2019;52:787-801 \begin{tabular}{ll|l} 
and BOI 10.33594/000000055 & @ 2019 The Author(s). Published by \\
Cell Physiol Biochem Press GmbH\&Co. KG
\end{tabular} \\ Kessler et al.: Paraspeckles in HCC}

Although it is well established that NEAT1 plays an important role in paraspeckle formation [28], details on the function of paraspeckles are as yet unknown. However, it is assumed that they locate RNAs inside the nucleus and are implicated in the reprogramming of a cell that takes place with differentiation. This may happen due to the inhibition of the expression of key proteins via nuclear RNA retention [34]. Paraspeckles were also reported to contribute to tumourigenesis by inhibiting DNA damage-induced cell death [35]. Although paraspeckles have been described in diverse cell lines [13], to our knowledge, our report is the first one showing paraspeckles and their induction in liver cells. NEAT1-202/v2 which constitutes paraspeckles - was elevated in nearly all of the analysed chemoresistant hepatoma cells. For cell lines showing induction of NEAT1_v1/202/v2 but not of NEAT1-202/ $v 2$ and NEAT1_v1/201/202/v2 RNA, an elevated expression of NEAT1_v1 seems probable. However, this assumption cannot be ultimately confirmed due to the lack of a unique sequence of NEAT1_v1 (Fig. 1). Although NEAT1_v1 cannot induce nuclear body formation by itself [28], it was suggested to increase the number of paraspeckles [11]. Another hypothesis is that NEAT1_v1 localises in non-paraspeckle foci (so called 'microspeckles'), which may carry paraspeckle-independent functions [35].

Our findings indicate an elevated expression of NEAT1_v1 in doxorubicin resistant HepG2 cells compared to sorafenib resistant HepG2 cells. Since paraspeckles were also detected in doxorubicin resistant HepG2 cells, which showed no increased expression of NEAT1$202 / v 2$, a positive association between NEAT1_v1 and the number of paraspeckles - as suggested previously [13] - seems to be likely. These results are consistent with previous findings on a link between NEAT1_v1/202/v2 and NEAT1-202/ $\checkmark 2$ expression and chemoresistance in several other

Table 2. Cut-off points for cytoplasmic and nuclear expression of PSPC1. Statistical analysis to determine cut-off points with receiver operator characteristic curve analysis. The points with the highest area under the curve (AUC) were cut-off points for cytoplasmic and nuclear PSPC1 expression (Fig. 6B)

\begin{tabular}{llll}
\hline Protein staining & Cut-off & AUC & $P$ \\
\hline PSPC1, cytoplasm & All & 0.575 & 0.100 \\
& $\geq 8$ & 0.583 & 0.069 \\
PSPC1, nucleus & All & 0.652 & $<0.001$ \\
& $\geq 7$ & 0.625 & 0.006 \\
\hline
\end{tabular}
tumour types [14] and extend them towards chemoresistance in HCC. IncRNA MALAT1/ NEAT2, which is located adjacent to the gene locus of NEAT1, was reported to have a similar role in chemoresistance [36-38]. Thus, a similar mechanism between the two lncRNAs has been suggested [39]. Interestingly, we observed strong correlations between NEAT1 and MALAT1 transcripts in the TCGA data set (Supplementary Fig. S5), suggesting further research in the connection of those genes.

Table 3. The association between clinicopathologic variables and the expression of PSPC1. AFP, a-fetoprotein; HBV, hepatitis B virus; HCV, hepatitis $C$ virus

\begin{tabular}{|c|c|c|c|c|c|c|}
\hline \multirow[t]{2}{*}{ Characteristics } & & \multirow[t]{2}{*}{ No. } & \multicolumn{2}{|c|}{ PSPC1, nuclear } & \multicolumn{2}{|c|}{ PSPC1, cytoplasm } \\
\hline & & & Positive & $\mathrm{P}$ & Positive & $\mathrm{P}$ \\
\hline \multirow[t]{2}{*}{ Sex } & Male & 139 & $71(51 \%)$ & 0.054 & $23(17 \%)$ & 0.159 \\
\hline & Female & 21 & $6(29 \%)$ & & $1(5 \%)$ & \\
\hline \multirow[t]{2}{*}{ Age, $y$} & $<55$ & 63 & $32(51 \%)$ & 0.586 & $7(11 \%)$ & 0.267 \\
\hline & $\geq 55$ & 97 & $45(46 \%)$ & & $17(18 \%)$ & \\
\hline \multirow[t]{2}{*}{$\mathrm{AFP}, \mathrm{ng} / \mathrm{mL}$} & $<100$ & 105 & $49(47 \%)$ & 0.61 & $15(14 \%)$ & 0.727 \\
\hline & $\geq 100$ & 55 & $28(51 \%)$ & & $9(16 \%)$ & \\
\hline \multirow[t]{2}{*}{ HBV } & Negative & 42 & $20(48 \%)$ & 0.939 & $10(24 \%)$ & 0.063 \\
\hline & Positive & 118 & $57(48 \%)$ & & $14(12 \%)$ & \\
\hline \multirow[t]{2}{*}{$\mathrm{HCV}$} & Negative & 150 & $71(47 \%)$ & 0.438 & $20(13 \%)$ & 0.022 \\
\hline & Positive & 10 & $6(60 \%)$ & & $4(40 \%)$ & \\
\hline \multirow[t]{2}{*}{ Liver cirrhosis } & Absence & 84 & $47(56 \%)$ & 0.037 & $15(18 \%)$ & 0.287 \\
\hline & Presence & 76 & $30(39 \%)$ & & $9(12 \%)$ & \\
\hline \multirow[t]{2}{*}{ Bilirubin, mg/dl } & $<0.7$ & 73 & $35(48 \%)$ & 0.967 & $7(10 \%)$ & 0.079 \\
\hline & $\geq 0.7$ & 87 & $42(48 \%)$ & & $17(20 \%)$ & \\
\hline \multirow[t]{2}{*}{ Albumin, ng/dl } & $<3.5$ & 21 & $10(48 \%)$ & 0.96 & $4(19 \%)$ & 0.577 \\
\hline & $\geq 3.5$ & 139 & $67(48 \%)$ & & $20(14 \%)$ & \\
\hline \multirow[t]{3}{*}{ Tumor stage } & I & 59 & 23 (39\%) & 0.165 & $9(15 \%)$ & 0.155 \\
\hline & II & 63 & 32 (51\%) & & $6(10 \%)$ & \\
\hline & III \& IV & 38 & $22(58 \%)$ & & $9(24 \%)$ & \\
\hline \multirow[t]{2}{*}{ Histologic grade } & Low & 101 & $46946 \%)$ & 0.393 & $16(16 \%)$ & 0.696 \\
\hline & High & 59 & $31(53 \%)$ & & $8(14 \%)$ & \\
\hline \multirow[t]{2}{*}{ PSPC1, cytoplasm } & Negative & 136 & $55(40 \%)$ & $<0.001$ & & \\
\hline & Positive & 24 & $22(92 \%)$ & & & \\
\hline
\end{tabular}


Table 4. Multivariate Cox regression survival analysis in 160 hepatocellular carcinoma patients. HBV, hepatitis B virus; HCV, hepatitis C virus; AFP, $\alpha$-fetoprotein; HR, hazard ratio. * Variables considered in multivariate analysis were age of the patients, AFP levels, albumin levels, TNM stage, histologic grade, nuclear expression of PSPC1, and cytoplasmic expression of PSPC1

\begin{tabular}{ccccc}
\hline Characteristics & OS & RFS & PR \\
& HR (95\% CI) & P & HR $\%$ CI $)$ & P \\
\hline Age, $\geq 55$ (vs $<55)$ & $1.650(1.014-2.685)$ & 0.044 & $1.645(1.093-2.476)$ & 0.017 \\
AFP $\geq 100 \mathrm{ng} / \mathrm{ml}(\mathrm{vs}<100 \mathrm{ng} / \mathrm{ml})$ & $1.574(0.990-2.502)$ & 0.055 & $1.795(1.208-2.668)$ & 0.004 \\
Tumor stage, I & 1 & 0.001 & 1 & $<0.001$ \\
II & $1.413(0.801-2.494)$ & 0.232 & $1.336(0.838-2.131)$ & 0.224 \\
III \& IV & $2.760(1.553-4.904)$ & $<0.001$ & $2.524(1.537-4.145)$ & $<0.001$ \\
PSPC1 nuclear positive (vs negative) & $1.978(1.252-3.125)$ & 0.003 & $1.566(1.069-2.295)$ & 0.021 \\
\hline
\end{tabular}

Beside the effect of NEAT1 on chemoresistance, it was recently reported that knockdown of NEAT1 increased apoptosis and reduced both viability and proliferation in different HCC cell lines $[15,16]$. Since we could not detect any paraspeckles in untreated, chemosensitive HCC cells, NEAT1 may also have additional, paraspeckle-independent functions related to cell viability [29]. Recent reports suggest NEAT1 to promote proliferation and metastasis by different mechanisms: targeting microRNAs as a competing endogenous RNA (ceRNA) / molecular sponge [40-42] and interacting with the transcription factor CDC5L [43] or the histone methyltransferase EZH2 [44].

NEAT1 expression has been shown to be upregulated in different human malignancies, including lung cancer, colorectal cancer, prostate cancer, breast cancer, and HCC [45]. However, the differentiation between the transcript variants of NEAT1 to our knowledge was never reported. We therefore decided to analyse the expression of the transcript variants of NEAT1 in human HCC tissue and were able to demonstrate that the transcript variants NEAT1-201, NEAT1-202/v2, and NEAT1-205 are elevated in HCC tissue in several hundred tumour samples compared to normal tissues. We were also able to confirm previous findings, in which an increased expression of NEAT1 for up to 95 HCC vs. non-cancerous liver tissues - as assessed by qPCR and primers detecting NEAT1_v1/202/v2 - was reported [30, 31]. Although NEAT1_v1/202/v2 expression has been suggested to be associated with poor prognosis in breast cancer, lung cancer, oesophageal squamous cell carcinoma, colorectal cancer, and HCC [16, 46-48], we could not confirm a significant association of the expression of NEAT1 transcripts with survival in HCC in this study. Interestingly, though, there are also reports that NEAT1 is downregulated in acute promyelocytic leukaemia [49].

Although the elevated expression of NEAT1 transcripts suggests NEAT1 as a clinical marker for HCC, there is one major issue regarding this aspect: the stability of NEAT1. In fact, a study performing a genome-wide analysis of long non-coding RNA stability found Neat1 to be "one of the least stable lncRNAs" [50]. We could confirm instability of NEAT1 in HepG2, Huh7, and PLC/PRF/5 cells by employing the transcriptional inhibitor actinomycin D resulting in a maximum half-life of 4 hours (Supplementary Fig. S6), which is substantially lower than that of other IncRNAs, such as H19, the half-life of which is over 10 hours [51]. Hence, expression analysis of NEAT1 in clinical practice may lead to incorrect results, while our data show that PSPC1 as a marker for NEAT1-dependent paraspeckle formation [28] may be a more valid marker for HCC prognosis. In addition, histological stainings represent an established diagnostic and prognostic technique in clinical practice worldwide. PSPC1 staining intensity was recently correlated with poor survival in different tumor types [52]. In the latter study the authors did not distinguish between nuclear and cytoplasmatic staining, though. In our HCC cohort, nuclear PSPC1 positivity was associated with the absence of liver cirrhosis and cytoplasmatic positivity was associated with HCV infection. Interestingly, hepatitis delta virus (HDV) replication was shown to induce translocation of PSPC1 protein from the nucleus to the cytoplasm. To our knowledge, no respective studies have been performed for HCV. Translocation of PSPC1 to the cytoplasm has been reported to coincide with enhanced RNA export during adipocyte differentiation [53]. Other members of the 


\section{Cellular Physiology Cell Physiol Biochem 2019;52:787-801 \begin{tabular}{ll|l} 
and Biochemistry $\begin{array}{l}\text { DOl: 10.33594/000000055 } \\
\text { Published online: } 5 \text { April 2019 }\end{array}$ & $\begin{array}{l}\text { O } 2019 \text { The Author(s). Published by } \\
\text { Cell Physiol Biochem Press GmbH\&Co. KG }\end{array}$ \\
\cline { 2 - 3 } &
\end{tabular} \\ Kessler et al.: Paraspeckles in HCC}

Drosophila behavior/human splicing (DBHS) protein family have been described to function cytoplasmatically [54, 55], thereby affecting chemosensitivity [55]. In summary, differences in nuclear and cytoplasmatic PSPC1 expression seem to be related to the cause of HCC and should be investigated in more detail in future studies.

In addition to NEAT1 and PSPC1 protein, we also found transcripts of the paraspeckleassociated proteins PSPC1, NONO, and RBM14 to be upregulated in HCC compared to non-cancerous liver tissue. All of these proteins have been reported to be associated with chemoresistance in different cancer cells $[35,56,57]$.

\section{Conclusion}

In conclusion, a detailed analysis of paraspeckle function in HCC might reveal NEAT1 and paraspeckle-related proteins as as clinical prognostic markers for HCC and potentially also as promising targets for the development of novel HCC therapies.

\section{Acknowledgements}

We acknowledge support by the Deutsche Forschungsgemeinschaft (DFG, German Research Foundation) and Saarland University within the funding programme Open Access Publishing. This work was supported by the Dr. Hilmer Stiftung - part of Deutsches Stiftungszentrum (to KH) and by the Else Kröner-Fresenius-Stiftung (2012_A250; to AKK and SMK). This work was further supported by the National Research Foundation of Korea (NRF) funded by the Korean government (MSIP) (No. NRF-2017R1A5A2015061 to KYJ). The results upon which this publication is based were partly funded by the Federal Ministry of Education and Research under the Project Number [01KU1216F] (to AKK). The responsibility for the content of this publication lies with the authors. This study obtained institutional review board approval from the Chonbuk National University Hospital, and the requirement for informed consent was waived (IRB number, CUH 2018-03-002).

\section{Disclosure Statement}

No conflicts of interest, financial or otherwise, are declared by the authors.

\section{References}

- 1 Bruix J, Han KH, Gores G, Llovet JM, Mazzaferro V: Liver cancer: Approaching a personalized care. J Hepatol 2015;62:S144-156.

- 2 Tang A, Hallouch O, Chernyak V, Kamaya A, Sirlin CB: Epidemiology of hepatocellular carcinoma: target population for surveillance and diagnosis. Abdom Radiol (NY) 2017;43:13-25.

- 3 De Angelis R, Sant M, Coleman MP, Francisci S, Baili P, Pierannunzio D, Trama A, Visser O, Brenner H, Ardanaz E, Bielska-Lasota M, Engholm G, Nennecke A, Siesling S, Berrino F, Capocaccia R: Cancer survival in Europe 1999-2007 by country and age: results of EUROCARE--5-a population-based study. Lancet Oncol 2014;15:23-34.

4 Yau T, Chan P, Epstein R, Poon RT: Evolution of systemic therapy of advanced hepatocellular carcinoma. World J Gastroenterol 2008;14:6437-6441.

5 Worns MA, Weinmann A, Schuchmann M, Galle PR: Systemic therapies in hepatocellular carcinoma. Dig Dis 2009;27:175-188.

6 Cheng Z, Li X, Ding J: Characteristics of liver cancer stem cells and clinical correlations. Cancer Lett 2016;379:230-238.

- 7 Hamilton G, Rath B: A short update on cancer chemoresistance. Wien Med Wochenschr 2014;164:456-460. 


\section{Cellular Physiology Cell Physiol Biochem 2019;52:787-801 \begin{tabular}{c|c|c|}
\hline DOI: 10.33594/000000055 & O 2019 The Author(s). Published by \\
\hline
\end{tabular} and Biochemistry Published online: 5 April 2019 Cell Physiol Biochem Press GmbH\&Co. KG \\ Kessler et al.: Paraspeckles in HCC}

- 8 Jiao M, Nan KJ: Activation of PI3 kinase/Akt/HIF-1alpha pathway contributes to hypoxia-induced epithelial-mesenchymal transition and chemoresistance in hepatocellular carcinoma. Int J Oncol 2012;40:461-468.

- 9 Zhao Y, Li H, Fang S, Kang Y, Wu W, Hao Y, Li Z, Bu D, Sun N, Zhang MQ, Chen R: NONCODE 2016: an informative and valuable data source of long non-coding RNAs. Nucleic Acids Res 2016;44:D203-D208.

- 10 Mao YS, Sunwoo H, Zhang B, Spector DL: Direct visualization of the co-transcriptional assembly of a nuclear body by noncoding RNAs. Nat Cell Biol 2011;13:95-101.

- 11 Clemson CM, Hutchinson JN, Sara SA, Ensminger AW, Fox AH, Chess A, Lawrence JB: An architectural role for a nuclear noncoding RNA: NEAT1 RNA is essential for the structure of paraspeckles. Mol Cell 2009;33:717-726.

- 12 Souquere S, Beauclair G, Harper F, Fox A, Pierron G: Highly ordered spatial organization of the structural long noncoding NEAT1 RNAs within paraspeckle nuclear bodies. Mol Biol Cell 2010;21:4020-4027.

13 Nakagawa S, Hirose T: Paraspeckle nuclear bodies - useful uselessness? Cell Mol Life Sci 2012;69:30273036.

14 Adriaens C, Standaert L, Barra J, Latil M, Verfaillie A, Kalev P, Boeckx B, Wijnhoven PW, Radaelli E, Vermi W, Leucci E, Lapouge G, Beck B, van den Oord J, Nakagawa S, Hirose T, Sablina AA, Lambrechts D, Aerts S, Blanpain C, et al.: p53 induces formation of NEAT1 lncRNA-containing paraspeckles that modulate replication stress response and chemosensitivity. Nat Med 2016;22:861-868.

- 15 Fang L, Sun J, Pan Z, Song Y, Zhong L, Zhang Y, Liu Y, Zheng X, Huang P: Long non-coding RNA NEAT1 promotes hepatocellular carcinoma cell proliferation through the regulation of miR-129-5p-VCP-IkappaB. Am J Physiol Gastrointest Liver Physiol 2017;313:G150-G156.

- 16 Liu Z, Chang Q, Yang F, Liu B, Yao HW, Bai ZG, Pu CS, Ma XM, Yang Y, Wang TT, Guo W, Zhou XN, Zhang ZT: Long non-coding RNA NEAT1 overexpression is associated with unfavorable prognosis in patients with hepatocellular carcinoma after hepatectomy: A Chinese population-based study. Eur J Surg Oncol 2017;43:1697-1703.

- 17 Schultheiss CS, Laggai S, Czepukojc B, Hussein UK, List M, Barghash A, Tierling S, Hosseini K, GolobSchwarzl N, Pokorny J, Hachenthal N, Schulz M, Helms V, Walter J, Zimmer V, Lammert F, Bohle RM, Dandolo L, Haybaeck J, Kiemer AK, et al.: The long non-coding RNA H19 suppresses carcinogenesis and chemoresistance in hepatocellular carcinoma. Cell Stress 2017;1:37-54.

18 Hoppstädter J, Diesel B, Eifler LK, Schmid T, Brüne B, Kiemer AK: Glucocorticoid-induced leucine zipper is downregulated in human alveolar macrophages upon Toll-like receptor activation. Eur J Immunol 2012;42:1282-1293.

- 19 Kiemer AK, Vollmar AM: Autocrine regulation of inducible nitric-oxide synthase in macrophages by Atrial Natriuretic Peptide. J Biol Chem 1998;273:13444-13451.

- 20 Vivian J, Rao AA, Nothaft FA, Ketchum C, Armstrong J, Novak A, Pfeil J, Narkizian J, Deran AD, MusselmanBrown A, Schmidt H, Amstutz P, Craft B, Goldman M, Rosenbloom K, Cline M, O'Connor B, Hanna M, Birger C, Kent WJ, et al.: Toil enables reproducible, open source, big biomedical data analyses. Nat Biotechnol 2017;35:314-316.

- 21 Li B, Dewey CN: RSEM: accurate transcript quantification from RNA-Seq data with or without a reference genome. BMC Bioinformatics 2011;12:323.

22 Kassambara A, Kosinski M, Biecek P, Scheipl F: Survminer: drawing survival curves using 'Ggplot2'. URL: https://CRANR-projectorg/package=survminer 2017.

23 Bosman FT, Carneiro F, Hruban RH, Theise ND: WHO classification of tumours of the digestive system. Lyon, France: International Agency for Research on Cancer, ed 4, 2010.

24 Edge SB, Byrd DR, Compton CC, Fritz AG, Greene FL, Trotti A: AJCC Cancer Staging Handbook. From the AJCC Cancer Staging Manual, ed 7, New York, Springer, 2010.

25 Allred D, Harvey JM, Berardo M, Clark GM: Prognostic and predictive factors in breast cancer by immunohistochemical analysis. Mod Pathol 1998;11:155-168.

26 Bae JS, Park JY, Park SH, Ha SH, An AR, Noh SJ, Kwon KS, Jung SH, Park HS, Kang MJ, Jang KY: Expression of ANO1/DOG1 is associated with shorter survival and progression of breast carcinomas. Oncotarget 2018;9:607-621.

27 Kim KM, Park SH, Bae JS, Noh SJ, Tao GZ, Kim JR, Kwon KS, Park HS, Park BH, Lee H, Chung MJ, Moon WS, Sylvester KG, Jang KY: FAM83H is involved in the progression of hepatocellular carcinoma and is regulated by MYC. Sci Rep 2017;7:3274. 


\section{Cellular Physiology Cell Physiol Biochem 2019;52:787-801 \begin{tabular}{c|c|c|}
\hline DOI: 10.33594/000000055 & O 2019 The Author(s). Published by \\
\hline
\end{tabular} and Biochemistry Published online: 5 April 2019 Cell Physiol Biochem Press GmbH\&Co. KG \\ Kessler et al.: Paraspeckles in HCC}

- 28 Naganuma T, Nakagawa S, Tanigawa A, Sasaki YF, Goshima N, Hirose T: Alternative 3'-end processing of long noncoding RNA initiates construction of nuclear paraspeckles. EMBO J 2012;31:4020-4034.

- 29 Li R, Harvey AR, Hodgetts SI, Fox AH: Functional dissection of NEAT1 using genome editing reveals substantial localization of the NEAT1_1 isoform outside paraspeckles. RNA 2017;23:872-881.

- 30 Guo S, Chen W, Luo Y, Ren F, Zhong T, Rong M, Dang Y, Feng Z, Chen G: Clinical implication of long noncoding RNA NEAT1 expression in hepatocellular carcinoma patients. Int J Clin Exp Pathol 2015;8:53955402.

- 31 Wang Z, Zou Q Song M, Chen J: NEAT1 promotes cell proliferation and invasion in hepatocellular carcinoma by negative regulating miR-613 expression. Biomed Pharmacother 2017;94:612-618.

32 Zerbino DR, Achuthan P, Akanni W, Amode MR, Barrell D, Bhai J, Billis K, Cummins C, Gall A, Giron CG, Gil L, Gordon L, Haggerty L, Haskell E, Hourlier T, Izuogu OG, Janacek SH, Juettemann T, To JK, Laird MR, et al.: Ensembl 2018. Nucleic Acids Res 2017;46:D754-D761.

33 Liu F, Chen N, Gong Y, Xiao R, Wang W, Pan Z: The long non-coding RNA NEAT1 enhances epithelialto-mesenchymal transition and chemoresistance via the miR-34a/c-Met axis in renal cell carcinoma. Oncotarget 2017;8:62927-62938.

- 34 Fox AH, Lamond AI: Paraspeckles. Cold Spring Harb Perspect Biol 2010;2:a000687.

- 35 Gao X, Kong L, Lu X, Zhang G, Chi L, Jiang Y, Wu Y, Yan C, Duerksen-Hughes P, Zhu X, Yang J: Paraspeckle protein 1 (PSPC1) is involved in the cisplatin induced DNA damage response - role in G1/S checkpoint. Plos One 2014;9:e97174.

- 36 Cai T, Liu Y, Xiao J: Long noncoding RNA MALAT1 knockdown reverses chemoresistance to temozolomide via promoting microRNA-101 in glioblastoma. Cancer Med 2018;7:1404-1415.

37 Xue D, Lu H, Xu H-Y, Zhou C-X, He X-Z: Long noncoding RNA MALAT1 enhances the docetaxel resistance of prostate cancer cells via miR-145-5p-mediated regulation of AKAP12. J Cell Mol Med 2018;22:3223-3237.

38 YiRen H, YingCong Y, Sunwu Y, Keqin L, Xiaochun T, Senrui C, Ende C, XiZhou L, Yanfan C: Long noncoding RNA MALAT1 regulates autophagy associated chemoresistance via miR-23b-3p sequestration in gastric cancer. Mol Cancer 2017;16:174-174.

39 West Jason A, Davis Christopher P, Sunwoo H, Simon Matthew D, Sadreyev Ruslan I, Wang Peggy I, Tolstorukov Michael Y, Kingston Robert E: The long noncoding RNAs NEAT1 and MALAT1 bind active chromatin sites. Mol Cell 2014;55:791-802.

40 Han D, Wang J, Cheng G: LncRNA NEAT1 enhances the radio-resistance of cervical cancer via miR-193b-3p/ CCND1 axis. Oncotarget 2018;9:2395-2409.

41 Liu X, Liang Y, Song R, Yang G, Han J, Lan Y, Pan S, Zhu M, Liu Y, Wang Y, Meng F, Cui Y, Wang J, Zhang B, Song X, Lu Z, Zheng T, Liu L: Long non-coding RNA NEAT1-modulated abnormal lipolysis via ATGL drives hepatocellular carcinoma proliferation. Mol Cancer 2018;17:90.

42 Qi L, Liu F, Zhang F, Zhang S, Lv L, Bi Y, Yu Y: IncRNA NEAT1 competes against let-7a to contribute to nonsmall cell lung cancer proliferation and metastasis. Biomed Pharmacother 2018;103:1507-1515.

43 Li X, Wang X, Song W, Xu H, Huang R, Wang Y, Zhao W, Xiao Z, Yang X: Oncogenic properties of NEAT1 in prostate cancer cells depend on the CDC5L-AGRN transcriptional regulation circuit. Cancer Res 2018;78:4138-4149.

44 Chen Q Cai J, Wang Q Wang Y, Liu M, Yang J, Zhou J, Kang C, Li M, Jiang C: Long noncoding RNA NEAT1, regulated by the EGFR pathway, contributes to glioblastoma progression through the $\mathrm{WNT} / \beta$-catenin pathway by scaffolding EZH2. Clin Cancer Res 2018;24:684.

45 Yu X, Li Z, Zheng H, Chan MT, Wu WK: NEAT1: A novel cancer-related long non-coding RNA. Cell Prolif 2017;50:e12329.

46 Chen X, Kong J, Ma Z, Gao S, Feng X: Up regulation of the long non-coding RNA NEAT1 promotes esophageal squamous cell carcinoma cell progression and correlates with poor prognosis. Am J Cancer Res 2015;5:2808-2815.

- 47 Choudhry H, Albukhari A, Morotti M, Haider S, Moralli D, Smythies J, Schodel J, Green CM, Camps C, Buffa F, Ratcliffe P, Ragoussis J, Harris AL, Mole DR: Tumor hypoxia induces nuclear paraspeckle formation through HIF-2alpha dependent transcriptional activation of NEAT1 leading to cancer cell survival. Oncogene 2015;34:4482-4490.

- 48 Yu X, Li Z, Zheng H, Chan MTV, Wu WKK: NEAT1: A novel cancer-related long non-coding RNA. Cell Prolif 2017;50:e12329. 


\section{Cellular Physiology Cell Physiol Biochem 2019;52:787-801

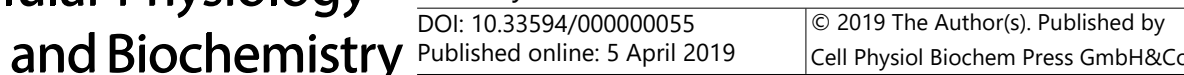 \\ Kessler et al.: Paraspeckles in HCC}

- 49 Zeng C, Xu Y, Xu L, Yu X, Cheng J, Yang L, Chen S, Li Y: Inhibition of long non-coding RNA NEAT1 impairs myeloid differentiation in acute promyelocytic leukemia cells. BMC Cancer 2014;14:693.

- 50 Clark MB, Johnston RL, Inostroza-Ponta M, Fox AH, Fortini E, Moscato P, Dinger ME, Mattick JS: Genomewide analysis of long noncoding RNA stability. Genome Res 2012;22:885-898.

- 51 Tybl E, Shi FD, Kessler SM, Tierling S, Walter J, Bohle RM, Wieland S, Zhang J, Tan EM, Kiemer AK: Overexpression of the IGF2-mRNA binding protein p62 in transgenic mice induces a steatotic phenotype. J Hepatol 2011;54:994-1001.

52 Yeh HW, Hsu EC, Lee SS, Lang YD, Lin YC, Chang CY, Lee SY, Gu DL, Shih JH, Ho CM, Chen CF, Chen CT, Tu PH, Cheng CF, Chen RH, Yang RB, Jou YS: PSPC1 mediates TGF- $\beta 1$ autocrine signalling and Smad2/3 target switching to promote EMT, stemness and metastasis. Nat Cell Biol 2018;20:479-491.

53 Wang J, Rajbhandari P, Damianov A, Han A, Sallam T, Waki H, Villanueva CJ, Lee SD, Nielsen R, Mandrup S, Reue K, Young SG, Whitelegge J, Saez E, Black DL, Tontonoz P: RNA-binding protein PSPC1 promotes the differentiation-dependent nuclear export of adipocyte RNAs. J Clin Invest 2017;127:987-1004.

54 Furukawa MT, Sakamoto H, Inoue K: Interaction and colocalization of HERMES/RBPMS with NonO, PSF, and G3BP1 in neuronal cytoplasmic RNP granules in mouse retinal line cells. Genes Cells 2015;20:257-266.

55 Ren S, She M, Li M, Zhou Q Liu R, Lu H, Yang C, Xiong D: The RNA/DNA-binding protein PSF relocates to cell membrane and contributes cells' sensitivity to antitumor drug, doxorubicin. Cytom Part A 2014;85:231241.

- 56 Kai M: Roles of RNA-Binding Proteins in DNA Damage Response. I J Mol Sci 2016;17:310.

- 57 Tsofack SP, Garand C, Sereduk C, Chow D, Aziz M, Guay D, Yin HH, Lebel M: NONO and RALY proteins are required for YB-1 oxaliplatin induced resistance in colon adenocarcinoma cell lines. Mol Cancer 2011;10:145-145. 